\title{
From Onto-sympathy and Ecological Awareness to Ethico-sympathy and Zoëlogical Interaction, Embodied Beings, and Pedagogy in an Anthropocene Age
}

\author{
MICHAEL PAULSEN
}

\begin{abstract}
It matters what world understanding we base educational theory and practice on. If we base it on an inherited Holocene scenic and human-centered world understanding, this leads to education understood as learning to optimize the use of resources only and solely for human needs. If we, on the other hand, base it on an emerging Anthropocene dialogical and life-centered world understanding, it leads to education understood as supporting students to become aware of the possibilities and value of being together with more-than-humans and to obtain experiences with how to co-create a joyful life. More specifically, it is argued that the onto-sympathy model proposed by Jane Bennett is based on a life-centered world understanding that might be helpful to foster needed ecological awareness within the field of education. However, this model needs to be complemented by an idealistic ethico-sympathy model, also based on a life-centered world understanding but paying more heed to cautious action, focusing on the possibility and value of zoëlogical interaction between humans and more-than-humans. If both models are used, it becomes more likely that we will begin to gain educational experiences with developing ethical relationships to more-than-humans and become able to co-create interspecies life-communities on a larger scale than today-both of which are needed more than ever in planetary history.
\end{abstract}

KEYWORDS: Education; Anthropocene; world understanding; onto-sympathy; ecological awareness; zoëlogical interaction; ethico-sympathy

\section{Introduction}

This article is about the concept of "onto-sympathy," proposed by Jane Bennett (2016; 2017a; 2017b; 2020), and "pedagogy in an Anthropocene age" (Paulsen, jagodzinski, \& Hawke 2022). ${ }^{1}$

1 The article is an elaboration of my talk, "Onto-sympathy, embodied beings and pedagogy in a (post) Anthropocene age-About the possibility of pedagogically mediated dialogue with more than humans," at the 
My aim is to consider theoretical responses to the Anthropocene and their pedagogical consequences. In this text, I discuss "new materialism" as a theoretical response to the Anthropocene through a critical assessment of Bennett's idea of onto-sympathy and what I see as its pedagogical implications and limitations. ${ }^{2}$ Part I of the article outlines the framework of this assessment. Part II unfolds the assessment of the onto-sympathy model from the perspective outlined in Part I. Part III sketches out how the onto-sympathy model could be advanced with more idealistic components, constituting an ethico-sympathy model as a reply to the critical remarks I develop with regard to Bennett's materialistic onto-sympathy model.

\section{Part I. How to understand and respond to the Anthropocene-Outlining a framework}

The map in Figure 1 indicates the framework and project I am working with and develop, apply, and adjust in dialogue with contemporary theory and practical experimentation (Paulsen 2019; Paulsen 2022c). In this article, I limit myself to a theoretical discussion of Jane Bennett's onto-sympathy model and its pedagogical potentials and limitations. As shown in Figure 1, the framework consists of three levels.

The first level is about a distinction between different understandings of the Anthropocene. The second level is about theoretical responses to these understandings. The third level is about practical, educational, and pedagogical but also political consequences of the

conference Futures of Education - Learning to Become 2021 (Futures-2021), April 22-23, 2021.Thanks to the conference organizers, participants, and especially Jesper Garsdal for the encouragement, comments, and valuable conversations.

2 I will not, in this article, go deeper into the differences between different advocates and strands of new materialism, such as between "speculative realism" and "new materialism" (Shaviro 2014:11). Following others (Ejsing 2021), I take for granted that Bennett is one of the main proponents of new materialism. By "new materialism," I understand the broad ambition to be to "elaborate new ways of grasping the world, outside of anthropocentric paradigms" (ibid.) from a new "materialistic perspective" (Bennett 2010: xvi), which is also not anthropocentric and thus different from, e.g., "Marx's notion of materiality - as economic structures and exchanges that provokes many other events" (ibid.). Bennett identifies it with an ambition to emphasize "the agentic contributions of non-human forces" (ibid). In a similar manner, Bryant describes new materialism as an ambition of supplementing (and thereby transcending the reductionism) of discursive theory and analysis, which, according to Bryant, does not take sufficiently (if at all) an account of material factors, "such as the calories a person gets a day" (Bryant 2014:1), and therefore only tells one part of the story and makes invisible "an entire domain of power" (ibid.:3). See also Coole and Frost 2010 and Dolphin and Tuin 2012 (despite their lack of references to Bennett), who state: "The term [new materialism] proposes a cultural theory that radically rethinks the dualisms [...] between nature and culture, matter and mind, the human and the inhuman [...] It thus has a profound interest in the morphology of change and gives special attention to matter (materiality, processes of materialization) as it has been so much neglected by dualist thought" (ibid.: 93). The link between "new materialism" and "the Anthropocene" is stated with clarity by Ejsing: "On the one hand, the advent of the Anthropocene signals the increased world-making powers of (some) human beings over others and over the natural environment. At the same time, its ecological crises and lack of effective human response also demonstrates the limits of human capabilities and illuminates that the Earth is indeed inhabited by many other things and forces, whose powers often outstrip humans many times over. This double movement of the Anthropocene invites us, the new materialist[s] argue, to start paying more attention to the dependencies, entanglements, and resonances that cut across and interrupt the categorical distinctions between humans and nonhumans, between culture and nature" (Ejsing 2021:42). 
theoretical ideas - and the basic understandings of the world of the Anthropocene they rely on and perhaps take for granted. To make my assessment as clear as possible, I will say something about these levels here in Part I, making explicit the perspective and hermeneutic framework I use to develop my argument from and with (following the methodological advice of radical hermeneutics, cf. Caputo 2018:247-248).

\section{(1) The Anthropocene}

(1.1) Meaning 1: The age in which Human

(1.2) Meaning 2: A shift in world activities affect the whole life-critical zone: understanding: from scenic and humanglobal warming, decreasing biodiversity etc. centered to dialogical and life-centered

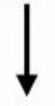

(2.1) Ressource optimization - we have to take better care of our ressources

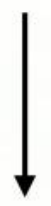

(3.1) Learn to take better care of ressources - learn to produce, master and optimize a limited number of ressources

\section{(2) Theoretical responses}

(2.2a) New materialism Mapping how bodies are entangled and part of one and the same living earth, affecting each other

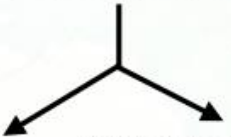

(2.2b) New idealism Paying heed to the possibility and value of dialogical relationships with morethan-human creatures
(3) Pedagogical consequences
(3.2a) Ecological
awareness. Build up
educational practises in
which awareness of
entanglement and
affections are developed

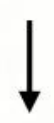

(3.2b) Life communities. Build up educational practises in which dialogical relationships between humans and more-thanhumans are developed

Figur 1 - Basic Understandings of the Anthropocene

The first and most important level is how one understands the Anthropocene, the age in which we live today (Paulsen 2019; Paulsen, jagodzinski, \& Hawke 2022). The perhaps most common, technical, and science-based understanding of the Anthropocene is that we now live in an age in which human activities, through technical mediation, affect globally, more than anything else, the whole life-critical zone of the earth (Latour 2017) and thereby give rise to mainly negative consequences we can read about every day in the newspaper-like global warming, decreasing biodiversity, environmental calamities, collapsing ecosystems, mass extinction, and the great acceleration (ibid.). There is more to say about the details of this understanding of the world, its prerequisites, historical roots, variations, defenders and enemies, and the knowledge regimes it leads to-but the limited point I want to make here is simply that it is possible to stay within this understanding of the Anthropocene, yet if one does that, it narrows how we can respond to our current situation and problems, both theoretically and practically. Thus, if we stay with this understanding only, the response tends to be exclusively about how we can optimize our (re)production and (re)uses of resources, including how we can pollute less, minimize global warming, secure our cities against climate consequences, create green technologies, and nudge our behaviors (Paulsen 2022a; 2022b; 2022c).

Further, if we think in line with the scientific, scenic, and human-centered worldview and its ideas about how to optimize resources, the pedagogical consequence is that we bring over a task to educational institutions, asking them to support students to learn to optimize humanity's resource consumption - that is, to learn to live on only one planet and not live as if 
we live on seven, ten, or even more planets or a planet much bigger than ours, but with the same number of people and needs (Nørreklit \& Paulsen 2022). There are, of course, good things to say about this worldview and its theoretical and practical implications, emphasizing resource optimization. First of all, it seems undeniable that we cannot keep on increasing our global resource consumption, pollution, and emissions-we must stop the "great acceleration" (if we can; ibid.).

Yet, besides the good things to say, there are limitations connected to this worldview as well. And to point these out, I will introduce another way of understanding the Anthropocene, which arises out of a critical analysis of the first interpretation of the Anthropocene (ibid.). If we begin to think of ourselves as living in an Anthropocene age, after the Holocene age, we begin to realize that most of our developments in the Holocene, like cities, democracy, technology, education, philosophy, and so on, have been based on a problematic worldview that has been scenic and human-centered to the extreme, and that this understanding has become dominant as the basis of all our main activities (Paulsen 2022c).

By "scenic," I mean that we have increasingly treated anything besides humans as mere resources or background or a scene for only human developments, thus putting the human being in the center. This includes putting some humans and some human aspects more in the center than others, and thus also treating many humans and human aspects as mere resources, background, or scene for the development of a limited number of privileged people and ways of life (cf. also Bennett 2010:ix and Braidotti 2013:66).

Of course, this has been complicated, with variations, deviations, and other alternative ways of relating to the world and others. My argument here is specifically that a certain and limited world understanding has become dominant in the late Holocene-that is, what is normally called historical time, from antiquity to the present. ${ }^{3}$ Yet it is precisely this very "environmental problem-producing" world understanding that is also the basis of the resource optimization response to the environmental problems. The only difference between the resource optimization response we see today and the earlier late-Holocene activities is that we now realize more clearly that the resources are limited and that the earth's systems are more fragile than previously thought. We realize, for instance, that we cannot sustain our emissions or our dropping waste in the oceans; this harms all the life on earth, including ourselves, and changes the earth's system in perhaps irreversible and uncontrollable, life-threatening ways (Steffen et al. 2011). Yet, one may wonder, and more and more people today do, I think, whether it is possible or desirable to try to solve the "uncontrollable" environmental problems with even more technical control and thus with the same outlook and basic assumptions and values that have created the problem in the first place (Nørreklit \& Paulsen 2022). This is what I mean with a "critical analysis" of the first meaning of the Anthropocene and the scenic and human-centered world understanding it relies on. It is beyond the scope of this article to document this critical analysis in philosophy, literature, popular culture, art, design, architecture, educational thinking, and elsewhere, but I think and have tried to show in other articles that this critical analysis, or "deconstruction," actually takes place within many spheres and begins

3 Besides the dominating the "technical" worldview (and, eo ipso, one's relationship to and understanding of "nature" as something separable from culture) in the late Holocene, in the Western world and later colonized, post-colonized, and globalized world, there have probably been several alternative and "competing" views circulating in the Holocene epoch, both Western and non-Western and Indigenous worldviews; yet it is beyond the scope of this article to investigate the potentialities of these (except from a short reference to Daoism in Part III of the article). But surely, potentialities for "new" and better ways of life and thinking should be sought along such lines as well. 
to move our whole cultural way of life and understanding the world in the direction of a new, more dialogical and life-centered world understanding (Paulsen 2022c; cf. also Chakrabarty 2015). Negatively speaking, the critical analysis consists of doubt about whether we can solve the environmental problems with the same means and understanding that have caused the problems in the first place, but also doubt about the genuine value of only treating the earth as a technical spaceship that we must control, optimize, and steer through self-produced calamities and perhaps unmanageable domino effects (Nørreklit \& Paulsen 2022).

When one begins to think like this, one begins to shift away from the scenic and humancentered world understanding and into a more dialogical and life-centered world understanding-or at least some alternative understanding of the world, however vague this might be. My aim here, however, is not to go deeply into an analysis of the new emerging world understanding (Paulsen 2019). What I want to do in this article is discuss some of the theoretical implications and responses to this shift toward a new life-centered and human-decentered world understanding.

In particular, I want to propose a soft distinction between two overlapping theoretical responses, namely new materialism and new idealism. It is important that it is a soft distinction, meaning that the two responses are not totally different in kind. Nevertheless, they emphasize different things. The new materialism movement (in my view) tries to understand and map how bodies are entangled and part of one and the same living earth - both human bodies and non-human bodies - and affect each other on a material level. It is within this line of thought that Jane Bennett's onto-sympathy model is situated, as I will go into in Part 2 of the article. The pedagogical consequence of this way of thinking is that education should place more emphasis on ecological awareness - that is, the perception of the whole world in which we live and form a part of, paving the way for affective involvements and sensibilities of this wholeness, and how we are entangled, materially, in different local ways that we, until now, have not been fully aware of and/or have somehow overlooked in our political and practical strategies and endeavours. We have focused too much on human actors understood as conscious beings producing discursive, intangible activities and immaterial linguistic-semiotic realities (Bryant 2014).

The pedagogical implication of new materialism, I would argue, is that educational institutions should develop practices in which an awareness of this entanglement is cultivated, supporting students to develop and sustain ecological affections and sensitivities-which calls for slow and time-intensive processes, and does not compart everything into separate subject matters.

My point is that this envisions a different school and educational practice than one in which the student only or mostly learns to optimize resource consumption. It also shares a materialistic interest with the resource optimization approach to schooling, but broadens the scope to affective relations to "things," and makes visible that resource consumption takes place on more levels and strata than one normally takes for granted in capitalistic and human-centered ways of living. But also, and perhaps even more importantly, it emphasizes that "phantasies of conquest and consumption" (Bennett 2010:ix) have been based on a "mechanical Western understanding of the material world as inherently passive and inert" (Ejsing 2021:42), which calls for a "philosophical reorientation that disrupts the ontological divide that separates the world into passive matter and active human beings" (ibid.).

On the other hand, both the resource optimization approach and the emphasis on ecological awareness put forward by new materialism differ from suggestions of new idealism, which I will not go into detail about here but only briefly set up as an alternative to new materialism. Thus, I propose that new idealism pays more heed to the possibility and value of dialogical 
relationships with more-than-human beings, understood as acting creatures, especially plants and animals, possessing their own interests, perspectives, and ways of life. This theoretical response, the idealistic one, is therefore about how we as humans can interact with other creatures, come into dialogue, and co-create interspecies relationships that benefit both parties, creating meaningful life through activities in which we do something valuable together (Nørreklit \& Paulsen 2022). ${ }^{4}$

This "new idealism" is not in strict opposition to "new materialism," which is also proven by the fact that one can easily find thoughts in new materialism that go in this direction as well-for instance, by changing and applying the concept of actor/agency to non-human forces and entities (Latour 2017). Nevertheless, the two strands of thought have different priorities. This becomes clear in their practical and pedagogical consequences. New idealism invites the creation of educational practices in which students gain experiences with trying to create dialogical relationships between humans and more-than-humans, where both can act and interchange, and in which students can learn to relate more kind-heartedly and cautiously to more-than-human beings as not only resources, but living, singular beings in their own right. This means that it puts emphasis on supporting the development of zoëlogical interactionand thus not just ecological awareness.

According to the idealistic way of thinking, it is only possible to develop emotional and ethical relationships to more-than-humans that commit us if we learn to approach more-thanhuman others not as mere objects of manipulation, but as actors and living beings with intrinsic values. Thus, it encourages educational institutions to support students to learn to interact with more-than-humans in cautious ways, but also to develop abilities to see the world from their point of view-how they see and live, their interests and what makes them happy, and also perhaps learn from more-than-humans and how they see and relate to us (Nørreklit \& Paulsen 2022).

In a difference from the resource-optimization response and the scenic and human-centered world understanding, the idealistic life-centered response argues that it is only by (re)cultivating ourselves as cautious caretakers, not just as conquerors and exploiters, that we can develop better emotional and perceptive relationships with the more-than-human world (ibid.). Further, it differs in the sense that it emphasizes possible new ways of living that have been overlooked in the late Holocene but which could enrich our lives. It does not, therefore, just say that we should reduce our footprint and our consumption, and put solar cells on our houses, and so forth. Rather, it points to radical shifts in how we live and relate to the earth, in the direction of creating a richer life together with more-than-humans than the one developed in the Holocene, which was based on a sharp distinction between "us" and "them" (ibid.).

This is the framework of my thought about our current situation, how we understand it differently today and therefore also respond differently, both on a theoretical and a practical level. I will now enter the middle of the map/framework, so to speak; consider more closely the onto-sympathy model proposed by Bennett; and in the end, come back to the larger framework. ${ }^{5}$

4 Proponents of new materialism might be sceptical of the simple expansion of Humanism to more creatures without a sufficient (self-)critique of the problematic assumptions of Humanism (Braidotti 2013:76-81). Yet my aim in this article is not to go further into this dispute, however relevant it is. See Paulsen 2022b for a thorough revision of Humanism.

5 The map drawn in this article is, of course, a simplification, as any map is. A more complex map would, for instance, pinpoint rhizomatic connections and expand the differentiation, including the difference between, for instance, new materialism and neo-Marxism, and so forth. Yet, for the pragmatic purpose of this article- 


\section{Part II. The Onto-Sympathy Model}

The basic idea in Bennett's onto-sympathy model is that humans are entwined with botanical life-or, more generally, with more than only human entities (see especially Bennett 2017a). ${ }^{6}$ Both human bodies and botanical bodies (trees, flowers, leaves, etc.) have a kind of vegetality and can communicate with each other on a material level. There is a certain overlap in materiality (Bennett 2017a:90) and a reaching out from each body toward what it senses to be its likeness "out there," according to Bennett (ibid.). This reaching out gives rise to a kind of solidarity, which Bennett calls onto-sympathy, between human bodies and non-human bodies: for instance, a human whose rhythm starts to sync with fluttering leaves (Bennett 2017a:92), or a human who detects a force of sympathy coming from a little pine needle (ibid.), or a human who eats an apple (which transforms both parties and which is possible only because the material elements are somehow friendly to each other or attracted to each other or can do something together; Bennett 2017a:89). Thus, onto-sympathy is a natural and vital force operating below, through, and beyond human bodies and experiences (Bennett 2017a:93)and the model therefore conceptualizes an impersonal cosmic tendency for bodies to follow attractions and communicate their presence to each other (Bennett 2017a:94). This implies that while Morton and other "dark" new materialists, paradoxically drawing on Heidegger, emphasize how everything withdraws and hides (Morton 2016:16), Bennett's model emphasizes the complementary process in which bodies become present to each other and sympathize with bodies they encounter, across species boundaries.

To make clear what is at stake, Bennett (2020:28-29) distinguishes her model of sympathy from Adam Smith's classical model of sympathy (in Smith's The Theory of Moral Sentiments from 1759). For Smith, according to Bennett, sympathy is a product of the sympathizer's own imagination. It is one's own subjective perception about how the other is feeling. When the other is unwell, I have only a weak feeling of it, and this weak feeling is a product of my own imagination, implying that I can never really feel the pain that the other feels, only imagine how it must be for the other (in analogy to myself) and sympathize with the other. Thus, sympathy for Smith is in the subject, as something the subject creates out of its own benevolence. Bennett's non-Cartesian model, on the other hand, stresses that sympathy is something that comes from outside, like a burglary, a material, affective injection into porous bodies. ${ }^{7}$ Thus,

to discuss the advantages and limitations of Bennett's onto-sympathy model-I find it not necessary to complicate the map further. See Paulsen, jagodzinski, and Hawke 2022 for more complex mapping of the Anthropocene and responses; also Latour 2017:10-14.

${ }^{6}$ In earlier texts, Bennett speaks of (onto-)sympathy (Bennett 2016), onto-sympathy (Bennett 2017a), or natural sympathy (Bennett 2017b), while in later texts she talks only of sympathy (Bennett 2020). In this article, I have kept the term "onto-sympathy" because it, in my view, signals more clearly the peculiarity of the concept of sympathy that Bennett develops and her ambition of applying sympathy to "all things" (Bennett 2017b:1197).

7 There is a striking similarity between Bennett's onto-sympathy model and the ethical thinking of Levinas (1996). For Levinas, however, the other is not breaking into "the house of the ego" by any physical force, but through a trans-physical ethical order, as Levinas put it, outgoing from the other, with the fundamental message "you must not kill me," before any physically actualized communication that presupposes this first ethical relationthus the Levinasian slogan, "ethics before ontology." In the context of this article, and the framework outlined in Part I, it could be added that the ethical thinking of Levinas-ethics before ontology-could be potentialized to articulate the idealistic response to the Anthropocene, extending "otherness" from the human sphere to all kinds of creatures. In Part III of the article, the proposed ethico-sympathy model derives from this Levinasian 
for Bennett, onto-sympathy is a more-than-human atmospheric vital force that affects bodies from the outside, a communicative transference that flows into bodies and tends toward an attachment that transcends any imaginative construct (Bennett 2020:30).

To go a step deeper into Bennett's model, I have, in Figure 2, sketched an encounter between a human body and a botanical body in which onto-sympathy might arise.

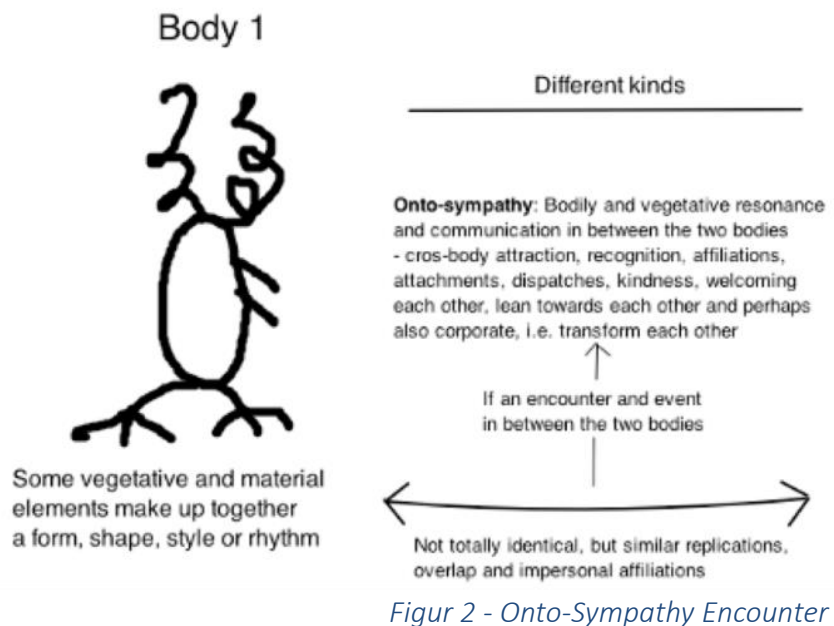

Body 2

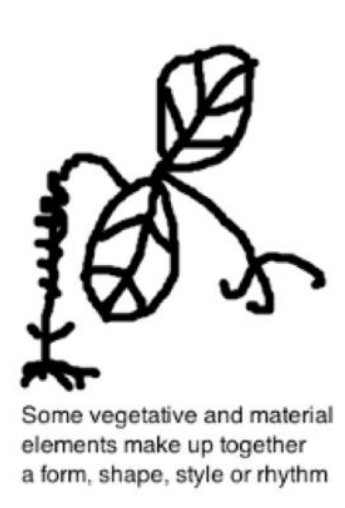

On the left side of the drawing is Body 1 , a human body, and on the right side is Body 2, a nonhuman body. The two bodies are different, but not totally different. ${ }^{8}$ There are some vegetative and material elements in the human body that make up a certain form, shape, style, or rhythm, which adds up to a certain way of being present. The same goes for the non-human body, which could be a plant, for instance, which also has some vegetative and material elements that make up a form, shape, style, or rhythm. Yet the crucial point, which is represented by the likeness on the material level of the two bodies in the naïve drawing, is that some of the elements and shapes of the two bodies are somehow similar. Bennett argues that when two such bodies encounter each other, it might happen that onto-sympathy arises on the material level, as a kind of body and vegetative resonance and communication between the two (Bennett 2017a:90). ${ }^{9}$ Bennett also calls this cross-body filiation, understood as an event or process that happens in between the two bodies (Bennett 2017a:92). The bodies welcome each other, lean toward each other, and perhaps cooperate-that is, transform each other. All or most of this is happening on a material level below the radar of explicit experience.

inspiration. Yet Levinas himself tends to limit ethical relations to (1) relations between humans, (2) defined negatively ("you must not ..."), and (3) in the format of order-like existential communication. Instead, I would suggest that we try to think of ethical relations that (1) include more-than-humans, (2) are defined in positive terms (like "you could choose to care for the other"), and (3) unfold in plural communication formats like invitations and offerings (see Paulsen 2022c for an in initial attempt in that direction).

8 Apparently, Bennett's inspiration for thinking in lines of similarities is the nonidentity strategy of Adorno 1973 (see Bennett 2010:13-17) and the strategy of Deleuze (2014:57-74) to transcend Hegelian polar distinctions (and thus the dialectics between something and its opposition). Yet, as I try to demonstrate in Part III of the article, I think Bennett's priority on similarities comes closer to a focus on identities than on the flow of differences, so to speak, and therefore has a significant flaw, or at least needs to be complemented by a co-focus on radical differences.

9 This idea of resonance is derived from Deleuze and Guattari 1987. See Roy (2003) for an application within the educational sphere. One can also find a similar concept of resonance in Rosa (2019), but without breaking radically with human exclusivism. 
Bennett's point is, I think, that if we become more aware of this material subconscious level and what is happening there, we also become more aware of and acquire important knowledge about how human and non-human bodies are entangled and "part of the same world," and come more into contact with ourselves, our bodies, and non-human bodies and realities as well, but also the affective potentials that flow on this level in between.

Bennett goes further and distinguishes between three levels or phases of onto-sympathy (Bennett 2017a:92-94). The lower level Bennett calls "gravitation" or "attraction" (ibid.). When a human, for instance, leans toward a plant, is drawn by it, it exemplifies something going on at this lower level. The important point is that onto-sympathy here arises because the plant affects the human body from outside and literally draws the human body closer by its affective power; and further, that such ordinary events are seldom taken account of on a political and pedagogical level, and likewise, in our practical life, we might not be aware of such powers happening below.

The second or "middle" level Bennett calls "corporation" (ibid.). This level or phase implies that two bodies mutually transform each other when, for instance, a human body smells or eats a plant; here the two bodies merge, and the plant is transformed into becoming a part of the human body, and the human body is transformed by the uptake of the plant.

The third level Bennett calls "annunciation" (ibid.), which happens when someone becomes distinctly aware of a kinship or overlap-when, for instance, the plant reminds a human being of something similar to himself. It is important to notice that this top level presupposes the two other levels: By becoming aware of the two first levels, we enter the third, and perhaps begin to think of ourselves and our relations to other beings in a new way and begin to learn from bodies other than our own, which are neither totally identical to our own nor totally different.

Finally, Bennett distinguishes between five kinds of onto-sympathy (Bennett 2017a; 2020). The first she calls "contagious pain" (Bennett 2020:30). This happens when a body senses the pain of another body by being infected by the pain of the other body and its suffering. The two bodies thus become connected through a kind of neuro-mimesis that creates affective entanglement.

The second kind of onto-sympathy Bennett calls "erotic attraction" (ibid.:35). This is a kind of onto-sympathy explicitly sensed and felt by a body in relation to other bodies in the form of sexual excitement or ecstatic pleasure - that is, a positive attraction and affection toward another body. Thus, a body is positively attracted to another body and obtains bodily pleasure by being close to this other body. This tends toward fusion and dissolution of the individual, according to Bennett, who also says that erotic sympathy is a force that ignores species boundaries. So, for instance, it can happen when a human foot meets the mineral earth and is attracted by this contact and likes to touch this earth's surface. Such sympathy obviously comes from outside of the body, namely from the body one is attracted to.

The third kind of onto-sympathy is called "body-part" (ibid.:37). This is a kind of onto-sympathy below the radar of emotional and sensory detection. Something is happening below, implicit and automatic, like the functioning of the heart and its onto-sympathy toward other body parts that it helps and connects to, and which could not function without the help of the heart. Thus, body parts can be friendly to other body parts and the body as such without anyone noticing it. If I understand Bennett correctly here, this means that, for instance, the heart is affected by other parts of the body and the body as well, on a non-sensory level, where the other parts and the body call the heart to be friendly to its bodily surroundings; the body needs the heart, and the heart is an answer to this need, one could perhaps say. 
The fourth kind of onto-sympathy is "barometric sensitivity" (ibid.:38). This is a kind of onto-sympathy that arises when a good atmosphere welcomes and affects the body. This also includes, according to Bennett, all of nature's non-discriminatory acceptance of all that is, a kind of "yes of the earth" to anyone-which affects each body situated on the earth. It's like walking in an autumn forest, which gets one into a certain sentimental mood, but also the fact that the earth as such, and perhaps one could also say the universe as such, is welcoming life and living bodies, is life-friendly, and thereby calls bodies to respond sympathetically to the forest, the earth, and the universe, by being thankful, for instance.

The fifth and last kind of onto-sympathy is "gravitational pull" (ibid.:42). This kind of ontosympathy arises out of a geological and cosmological set of attractions, simply by the fact that all matter attracts all matter, but completely impartially, without any care or concern at all, which also pushes the concept of onto-sympathy to its limit.

It is important to add that, of course, Bennett is aware that bodies can be hostile toward each other and not only sympathetic. In fact, Bennett talks about an alchemy of affects (Bennett 2020:61). Onto-sympathy is only one affect among a whole ecology of affects, often blended and mixed, pulsating, and changing in complex, interrelated ways. In this article, it is only my aim to discuss the onto-sympathy concept and not this wider scope of affects. Nevertheless, it is important to keep in mind that bodies are not just sympathetic, according to Bennett. What she argues is only that they can sympathize with each other, among other things, and that such sympathies occur and are generated in the first place by something outside a body, initiated by other bodies affecting the body that become sympathetic (or are invited to sympathize).

\section{Part III. Discussion: Political-pedagogical consequences and the ethico- sympathy model}

Perhaps we see the onto-sympathy model more clearly if we turn toward its practical and political consequences. According to Bennett, the model makes us more interested in vegetable life in which we can participate (Bennett 2017a:91). We become more aware of overlap in capacities between human bodies and non-human bodies. Both manifest the same life-force.

Bennett points to the example of Darwin and his drawings of how some plants climb and move, and perhaps also how some plants look like insects or could be drawn in a way that makes similarities between plants and animals (and humans as well) more visible to us (Bennett 2017a:97-102). This can make us more aware of the resemblances in shapes, forms, and rhythms. By drawing and perhaps exaggerating such resemblances, students could obtain help to read non-human modes of expression and enter onto-sympathy with non-human beings, becoming more aware of similarities between ourselves and plants, and our similar capacities.

According to Bennett, such efforts and experimentations, on a larger scale, give rise to a kaleidoscopic shift in everything you see, hear, smell, touch, taste, and think (Bennett 2017a:103). Furthermore, it makes the existence of the web of cross-body communication a little more sensible, which, I would suggest, might also change our self- and world-understanding and way of being in the world.

If we try to extend the consequences to the educational sphere, I would like to add that we can think of an educational practice in which students are encouraged to pay attention to and become aware of non-human bodies and their capacities. In such a practice, students are encouraged to slow down, take careful notice, and be touched by what they share with other bodies, becoming aware of the overlap and onto-sympathy going on below. This will invite 
students to become more attentive to their surroundings and more attuned to entanglements. This involves one's own imagination, yes, but it works upon what comes from elsewhere and reveals virtual friendships subsisting across different kinds of bodies. According to Bennett, it opens us to the beauty all bodies have just by "being there" and not turning away from them (Bennett 2016:616). It therefore helps us to cultivate trans-individual receptivity, affectivity, and solidarity. This practice is basically democratic because it pays attention to all bodies, including ordinary bodies, revealing commonness, cultivating the dignity and value of the common, and training our attention to overlooked bodies-including what is otherwise excluded (ibid.:607).

Though I agree on the positive value of these practical consequences, I also have three critical remarks, pointing out some limitations of the model proposed by Bennett that point toward the need to complement the model with another that I call an ethico-sympathy model, which is based on more idealistic components.

The first critical remark is that the onto-sympathy model focuses too much on similarities (despite differences) between human bodies and non-human bodies. It therefore does not value differences radically enough. Following Bennett, the other body has value because it is similar to our own. But, thereby, Bennett does not pay enough attention to the value of radical otherness. One could argue (following and expanding the ethical thinking of Levinas [Levinas 1996; Paulsen 2022c]) that it is only because the other (the non-human, for instance) is radically different from me that I have an ethical (i.e., a non-egological) relationship to the other. Further, it might be the otherness of the other that attracts me and that I sympathize with in the first place. And because we are different, we might be able to do joyful things together that would have been impossible if we were more similar. Therefore, we need to complement the model with another model that focuses on differences as valuable in themselves: a model of sympathy based on differences rather than similarities, and a model that takes account of radical otherness, meaning that each singular creature is appraised as unique and thus different from all other beings, including me. This demands that I take care of this irreplaceable being, or at least not destroy it-that is, that I listen to the call coming from the other on an existential ethical plane, which calls me to respond to each creature with gratitude and responsibility. It is, of course, possible to ignore this call. The point is only that ethical sympathy primordially arises only when such a call is heard, and that this call does not derive from similarities but radical differences. One could even go so far as to say that a model of sympathy that is only based on the ontological foundation of similarities risks racist implications.

My second remark is that the onto-sympathy model focuses too much on bodies, not on what it means to be a some-body, that is, a creature. Bennett does not distinguish between, for instance, trees or leaves (Bennett 2017a:92 ff.). Not acknowledging this distinction, or blurring it, creates a problem on a practical and ethical-political level. That some of the materials inside my body can affect and are being affected by other materials in other bodies is, after all, not a big surprise. But even more importantly, the onto-sympathy model helps us to become more aware of entanglement, but not why we should begin to form ethical and responsible relations to other creatures (as also stressed in my first remark). Just because an apple tastes good, for example, does not mean that we have an ethical obligation to care for the apple and protect its life as a value in itself. Therefore, what is lacking in the model is a theory of both human and more-than-human creatures, understood as embodied beings who can relate to each other as different and unique (emergent) creatures, not just as bodies consisting of similar materials that can affect and are being affected by each other.

My third and last critical remark is that the onto-sympathy model conceptualizes communication as "producing effects on each other," but this implies a too-simplistic theory of 
communication, the so-called transmission model (Luhmann 1996). In addition, it focuses on communication that operates below the radar of sensation and experience. The model, therefore, leaves out more advanced forms of communication that can happen between creatures through symbolic interaction, making it possible for creatures to communicate with each other and enter dialogue without necessarily affecting each other directly. Thus, Bennett does not distinguish between a kind of communication where the parties directly change each other on a material level and a kind of communication where the parties interact only symbolically and where changes in each participant are only achieved indirectly. In the last case, which is not fully taken into account in the onto-sympathy model, the symbolic interaction opens and gives rise to freedom between the creatures participating in the interaction-and this freedom is only and can only be established through this kind of communication. It is only because of such freedom and the affirmed radical gulf between the participants that ethical relations can make sense, because it is only so that the other can be itself and that I can respond as myself to the other. Thus, the upshot is that the communication part of the model is too simple and does not take into account all the communicative possibilities relevant to fostering sympathy between beings.

Summarizing the critical remarks, I would argue that we need to complement the ontosympathy model with an ethico-sympathy model, consisting of components that pay more attention to the following:

1. The value and productive role of differences and especially differences between singular, unique creatures and their creations (based on the idea and assumption that the other does not primarily receive its value because the other is similar, but because the other is radically different and unique)

2. The possibility and value of encounters between embodied beings, on the level of creatures, who can form ethical, binding relations through dialogue (based on the idea that creatures are embodied beings and ethics only make sense between such distinct beings)

3. The possibility and value of communication with others, not just through a kind of affective transmission, but first of all as a kind of symbolic interaction that provides the freedom to be together and do things together, without necessarily changing each other directly (based on the idea and assumption that primordial freedom derives from symbolic interaction and not from a modus of one-way causal transmission).

To give a hint of the possibility and character of such an ethico-sympathy model emphasizing symbolic interaction, and the value and creation of life-communities between humans and more-than-humans, I will end Part III by giving an example of interspecies dialogue and hereafter highlight the practical consequences.

I take this example from the Netflix movie My Octopus Teacher. In this movie, a man, Foster, dives every day for a year at the same spot. Through these journeys, he comes across a young octopus that he comes to know for almost its entire lifespan (one year). In the beginning, Foster only visits the den of the octopus. After many days, the octopus makes contact with Foster, and a relationship of care and curiosity develops. The octopus begins to touch Foster, plays with him, observes, hides, and seeks his help. A relationship of trust is 
established, and the octopus invites Foster into her world. When the octopus finally dies, Foster is moved and mourns for a long time over the loss of his life companion. ${ }^{10}$

I agree with Bennett that many things are happening in this example on a purely material level, but I would like to add and emphasize that something is also going on at the level of the two creatures-subjectivities, one could say, in the symbolic interaction between Foster and the octopus. Many things could be noticed here (Paulsen 2022a; Nørreklit \& Paulsen 2022), yet I want to point out a few significant things in order to make my case. First, it takes a lot of time for Foster to make the encounter possible. He dives every day for a full year, and many days pass before the octopus makes contact. In addition, Foster, by his own account, shifts from being a visitor to becoming a part of the environment, which is a huge difference. In ordinary post-Holocene mainstream education, such a shift does not normally take place because it restricts students to only learn from the position of being visitors in relation to morethan-humans. Yet there are important things to learn, both facts and values, which can only be learned by becoming a full member of an environment and by entering relationships with more-than-human others (Paulsen 2022a). Furthermore, Foster waits for the octopus to make contact, which could be argued to be a form of what is called a Wu-Wei strategy in old Chinese Daoism (Girardot et al. 2001): a kind of active non-action method of relating to the octopus, allowing the octopus to be the initiating party, which allows for a dialogical relationship that takes form between these two unique, singular beings, slowly creating a life-community in which both can participate, enjoy, and be and do things together. Through this, Foster learns a lot, not only about the octopus but, perhaps even more importantly, also about himself and his capacities, about life and what matters, and creates true life value and enjoyment.

All this, I would argue, is happening in and through the symbolic interaction between Foster and the octopus (see more details in Nørreklit \& Paulsen 2022), which is not sufficiently taken into account in Bennett's materialistic model of onto-sympathy. Yet this is not to deny the relevance of Bennett's model. Many similarities between Foster and the octopus, on a material level, can be detected and analysed with the help of Bennett's model: both Foster and the octopus are intelligent and sensitive creatures, curious, playful observers with extraordinary bodily capacities. My argument is focused on how the life-relationship they create is also, first, based on radical differences: it is only because they are different from each other, being two different, singular, unique beings, each one irreplaceable, that they can develop their unique emotional, personal, and ethical relationship. It is this specific and unique octopus that Foster learns to know and care for and meet with day after day, and it is this specific man, Foster, who the octopus begins to trust and welcome. Second, they are not just bodies or organs; they are embodied beings - that is, creatures - who can withdraw and respond to each other in different ways, making and reading signs, and thus form a dialogical relationship and a unique life-community. Third, this is not happening only through purely materialistic affective transmission, but first of all through symbolic interaction that gives both parties freedom to enjoy, without necessarily changing each other-for instance, when Foster allows the octopus to decide for herself whether she wants to make contact or not. Only then do ethical responsibilities become possible and meaningful, because of each dialogue partner's absolute irreplaceability; and paradoxically, it is only because they renounce direct influence on each other

10 I have chosen this example, in which a meeting between a human and an animal takes place, because it clearly makes visible the symbolic interaction I want to demonstrate. Yet, in Nørreklit and Paulsen 2022, we also exemplify with interaction between humans and plants in order to say that the argument does not necessarily rely on what Coccia 2019 (following Arbor) calls "animal chauvinism" - the assumption of the primacy of animal life over plant life. 
that they can affect each other on a much deeper transformative level-that is, to begin to care, and mourn, and sense themselves, too.

But again, to make my argument correctly, this does not out rule that affective transmissions, material attractions, and the levels of onto-sympathy that Bennett suggests also take place; rather, I would propose that the symbolic ethical and existential interaction rely on, modify, transform, and transgress the material levels of onto-sympathy. When, for instance, the octopus makes contact, she does it with her arms (appendages) and with her suckers, touching the body of Foster, and perhaps the two bodies and elements in the two bodies could be argued to make each other sympathetic to one another in the sense of onto-sympathy proposed by Bennett. What is happening between the octopus and Foster, however, is not reducible to this. Rather, the mere physical touch and bodily encounter is encapsulated in a wider symbolic encounter, which relies on and is transformed by, but also transforms, the meaning of the purely physical elements and processes; and first, by taking account of this symbolic extra- or metaphysical interplay and transformation, it is possible to understand the encounter as "contact" and "friendly meeting" in the full ethical sense of these words.

I will end Part III with my deduction of practical, political, and especially educational consequences of complementing a focus on onto-sympathy with my ethico-sympathy model of symbolic interspecies interaction - that is, for instance, to begin to think about how to create educational (but also other kinds of practical and political) practices and spaces that aim at developing interspecies life communities and ethical, binding dialogue between humans and more-than-humans. In such practices, students could be encouraged and supported to gain experiences with creating interspecies life-communities through building up dialogical relationships to all kinds of creatures (plants, animals, landscapes, environments). Such dialogues do not mean that all creatures are similar; rather, it means enjoying others' otherness (enjoying that we are different and enjoying our differences) taking upon us the responsibility of caring for others in their irreplaceable otherness and differences especially in that more-thanhumans are different and that these differences are exactly what has value and make life so rich-and make us happy to witness, and relate to, and be part of. Yet to build up such lifecommunities and dialogue with more-than-humans takes time-perhaps years, perhaps a whole lifetime or more, depending on what species the students and their teachers turn toward. Further, this calls for a radical reorganization of the post-Holocene school (and the whole inherited post-Holocene society); instead of teaching mostly in classrooms, separated from everything else, excluding all other creatures from being potential dialogue partners, a zoëlogical school-setting (i.e., an ethical, life-centered setting) is needed in which, for instance, school hours take place in a forest, in which the teaching and the school are resituated and relocated to the environment, and in which students try to develop life-communities and dialogical relationships with more-than-humans in many different ways (Nørreklit \& Paulsen 2022; Paulsen 2022a). Such a practice can be combined with the slow-attention practice suggested by the onto-sympathy model of Bennett, making it possible to recognize similarities and differences across embodied beings participating in evolving life-communities, and thus becoming more aware of entanglements, but also-inspired by the ethico-sympathy modelbecoming more able to do something together across species boundaries and produce and enjoy life together. On a political level, I think such a combination of newly increased ecological awareness and newly expanded zoëlogical interaction creates a stronger model of a desirable political form of life than, on its own, the model that Bennett suggests. On an educational 
level, I think that students, through this double emphasis on ecological awareness and zoëlogical interaction, can learn better (than older post-Holocene generations) to relate more carefully and productively to more-than-humans, each other, and themselves, and to get more and better experiences with how to create an enjoyable life together across differences.

\section{Conclusions: Making ontology and ethics stand side by side}

First, I have argued that it matters, educationally, what world understanding we base educational theory and practice on. If we base it on an inherited Holocene scenic and human-centered world understanding, this leads to education understood mainly as learning to master and optimize our use of resources. If we, on the other hand, base it on an emerging Anthropocene dialogical and life-centered world understanding, it leads to education understood as supporting us to become more aware of the possibilities and values of being together with more-than-humans and to gain experiences with how we might be able to co-create a joyful life across different species. Second, I have shown that the onto-sympathy model proposed by Jane Bennett as an example of new materialism might be helpful to foster ecological awareness through a slow-sensing strategy. But also, I have argued that this model needs to be complemented by a more idealistic ethico-sympathy model, which focuses more on the possibility and value of zoëlogical symbolic interaction and cautious dialogue between different humans and more-than-human creatures (and between humans and humans). Only thus does it become likely that we will begin to obtain educational experiences with developing ethical, binding relationships to more-than-humans and be able to co-create, if possible, more sustainable interspecies life-communities together, on a larger scale than today.

\section{Literature}

Adorno, T. (1973). Negative Dialectics. Continuum.

Bennett, J. (2010). Vibrant Matter: A Political Ecology of Things. Duke University Press.

Bennett, J. (2016). Whitman's Sympathies. In Political Quarterly, 63(3), 607-620.

Bennett, J. (2017a). Vegetal Life and Onto-sympathy. In Entangled Worlds (pp. 89-110). Fordham University Press.

Bennett, J. (2017b). Mimesis: Paradox or Encounter. MLN (Comparative Literature Issue), 132(5), 1186-1200.

Bennett, J. (2020). Influx and Efflux: Writing Up with Walt Whitman. Duke University Press.

Braidotti, R. (2013). The Posthuman. Polity Press.

Bryant, L. (2014). Onto-cartography. Edinburgh University Press.

Caputo, J. (2018). Hermeneutics. Facts and Interpretation in the Age of Information. Penguin Books.

Chakrabarty, J. (2015). The Human Condition in the Anthropocene. The Tanner Lectures in Human Values.

Coccia, E. (2019). The Life of Plants: A Metaphysics of Mixture. John Wiley \& Sons.

Coole, D., \& Frost, S. (2010). New Materialisms: Ontology, Agency, and Politics. Duke University Press.

Deleuze, G. (1994). Difference and repetition. Bloomsbury.

Deleuze, G., \& Guattari, F. (1987). A Thousand Plateaus: Capitalism and Schizophrenia. University of Minnesota. 
Dolphin, R., \& Tuin, I. (2012). New Materialism: Interviews and Cartographies. Open Humanities Press.

Ejsing, M. (2021). Approaching the Edge: Towards a New Materialist Theory of Democracy for the Anthropocene. Copenhagen University.

Girardot, N., Miller, J., \& Xiaogan, L. (Eds.). (2001). Daoism and Ecology. Harvard University Press.

Latour, B. (2017). Facing Gaia. Eight Lectures on the New Climate Regime. Polity Press.

Levinas, E. (1996). Basic Philosophical Writings. Indiana University Press.

Luhmann, N. (1996). Social Systems. Stanford University Press.

Morton, T. (2016). Dark Ecology - For a Logic of Future Co-existence. Columbia University Press.

Paulsen, M., \& Nørreklit, L. (2022). To Love and Be Loved in Return - Towards a Post-Anthropocene Pedagogy and Humanity. In Paulsen, M., jagodzinski, j., \& Hawke, S. (Eds.), Pedagogy in the Anthropocene-Re-Wilding Education for a New Earth. Palgrave Macmillan.

Paulsen, M. (2019). Understanding the Anthropocene World: Contemporary Difficulties. Proceedings of Pragmatic Constructivism, 9(2), 16-21.

Paulsen, M. (2022a). Cautiousness as a New Pedagogical Ideal in the Anthropocene. In Rethinking Education in Light of Global Challenges: Scandinavian Perspectives on Culture, Society and the Anthropocene. Routledge.

Paulsen, M. (2022b). From Late Holocene to Early Anthropocene Educational Thinking: Humanism Revisited. In Rethinking Education in Light of Global Challenges: Scandinavian Perspectives on Culture, Society and the Anthropocene. Routledge.

Paulsen, M. (2022c). The Plateau of Learning in the Anthropocene - How to Relate Differently to the Earth. In Kergel, D. (Ed.), The Great Book of Learning. Routledge.

Paulsen, M., jagodzinski, J., \& Hawke, S. (Eds.). (2022). Pedagogy in the Anthropocene: ReWilding Education for a New Earth. Palgrave Macmillan.

Rosa, H. (2019). Resonance: A Sociology of Our Relationship to the World. John Wiley \& Sons.

Roy, K. (2003). Teachers in Nomadic Spaces. Peter Lang.

Shaviro, S. (2014). The Universe of Things: On Speculative Realism (Vol. 30). University of Minnesota Press.

Steffen, W., Grinevald, J., Crutzen, P., \& McNeill, J. (2011). The Anthropocene: Conceptual and Historical Perspectives. Philosophical Transactions of the Royal Society A: Mathematical, Physical and Engineering Sciences, 369(1938), 842-867. 